\title{
A Study on Influencing Factors of Commercial Housing Price Based on Eviews in Shaanxi Province
}

\author{
Wang Wei-tong \\ College of Mathematics \& Statistics, Hebei University of Economics and Business, Hebei, China \\ 1479156429@qq.com
}

\begin{abstract}
The problem of housing prices has always been a hot spot in the whole society, which is closely related to the development needs of individuals, families and the whole society. In recent years, Shaanxi as a western region rapid development, housing prices continue to rise and become a hot topic of special concern to the public. Taking Shaanxi as an example, this paper selects the statistical data of commercial housing from 2008 to 2018 to establish econometric model, and uses EViews software to establish stepwise regression and White heteroscedasticity test to study the influencing factors of housing price rise in Shaanxi. And put forward the relevant suggestions.
\end{abstract}

Keywords: commodity price, econometric model, EViews

\section{INTRODUCTION}

Since the abolition of housing physical distribution policy in 1998, China's real estate industry has entered a new era, housing prices are also rising at an alarming rate. the housing prices in beijing) are as high as 100000 yuan per meter. Throughout China, from first-tier cities to second-tier cities, from coastal areas to the western border, no matter what kind of places, housing prices are in a rising trend[1]. Among them, Shaanxi's housing prices in the western region are also rising at an amazing rate[2]. This paper studies the factors and ways that leading to the soaring price of commercial housing, and gives some reasonable suggestions.

\section{MODEL DESCRIPTION}

The price of commercial housing is not only affected by the above factors, but also by the supply and demand situation, the degree of competition, consumer preference, market expectation and the management strategy of real estate enterprises as other commodities. But different from ordinary commodity, commercial housing also has the characteristics of long construction period, large value, fixed space and so on, so its price change law is also different from the general commodity price law.[3]

\subsection{Selection of variables and data sources}

Regional GDP (100 million yuan): From the general phenomenon, the higher the regional GDP, the higher the regional economy, the higher the house price, so there should be a positive correlation between the two index.

Average wage of urban employed persons (yuan): It shows that the degree of wage income of workers in a certain period is the main index to reflect the wage level of employed personnel. The two should be positively related.

Consumer price index (last year $=100$ ): Through this index, we can observe and analyze the influence of retail prices of consumer goods and price changes of service items on the actual living expenses of urban and rural residents

Total output value of construction industry (100 million yuan): the total output value of construction industry is the sum of construction products and services produced by construction enterprises in monetary form in a certain period of time.

The data comes from the Statistical Yearbook of Shaanxi Province. This paper selects the statistical data from 2008 to 2018, and the variables are composed of the above four factors.

\subsection{Description of econometric modelling}

Assuming that the average price of commercial housing in Shaanxi Province is $Y_{i}$ 
Total output value of Shaanxi Province is $x_{1}$

Average wage of urban employed persons in Shaanxi Province is $x_{2}$

Consumer Price Index of Shaanxi Province is $x_{3}$

Total output value of construction industry in Shaanxi Province is $x_{4}$

\section{CONSTRUCTION OF MULTIVARIATE MODELS}

Assuming that the average price of commercial housing in Shaanxi Province is $Y_{i}$, total output value of Shaanxi Province is $x_{1}$, average wage of urban employed persons in Shaanxi Province is $x_{2}$, consumer Price Index of Shaanxi Province is $x_{3}$, total output value of construction industry in Shaanxi Province is $x_{4}$, the total output value of construction industry $\beta_{0}, \beta_{1} \beta_{2} \beta_{3} \beta_{4} U_{i}$ is the coefficient, and $U_{i}$ is a random disturbance item.

$$
Y_{i}=\beta_{0}+\beta_{1} X_{1}+\beta_{2} X_{2}+\beta_{3} X_{3}+\beta_{4} X_{4}
$$

\subsection{OLS estimated parameters}

A linear model based on the above equation

Table 1. Parameter Estimates Table

Included observations: 12

\begin{tabular}{ccccc}
\hline \hline Variable & Coefficient & Std.Error & t-Statistic & Prob. \\
\hline \hline C & -15059.68 & 10044.20 & -1.499340 & 0.1775 \\
X1 & 0.170013 & 0.268977 & 0.632071 & 0.5474 \\
X2 & -0.022402 & 0.141564 & -0.158248 & 0.8787 \\
X3 & 156.4341 & 93.10021 & 1.680277 & 0.1368 \\
X4 & 0.617967 & 0.683473 & 0.904157 & 0.3960 \\
\hline \hline R-squared & 0.948644 & Mean dependent var & 4921.123 \\
Adjusted R-squared & 0.919297 & S.D.dependent var & 1625.334 \\
S.E.of regression & 461.7281 & Akaike info criterion & 15.40217 \\
Sum squared resid & 1492350. & Schwarz criterion & 15.60421 \\
Log likelihood & -87.41300 & Hannan-Quinn criter. & 15.32736 \\
F-statistic & 32.32574 & Durbin-Watson stat & 1.898957 \\
Prob (F-statistical) & 0.000133 & & & \\
\hline \hline
\end{tabular}

The results showes that the $p$-values of coefficient $t$ test is greater than 0.05 , and the original hypothesis is accepted, that is, the parameter estimate is significantly zero. The $\mathrm{F}$ test $\mathrm{p}$-value of the equation population is $0.000133<0.05$, and the model is significant. However, the economic significance can not be tested, indicating that the model has multiple collinearity and needs to be corrected. $x_{2}$

\subsection{Model testing and revision}

\subsubsection{Test and Correction of Multiple Collinearity}

Conjecture that the model has multiple collinearity, and use EViews software to obtain the simple correlation matrix between explanatory variables, as shown in figure 1.

Table 2. Simple correlation matrix between explanatory variables

\begin{tabular}{l|llll}
\hline & X1 & X2 & X3 & X4 \\
\hline X1 & 1.000000 & 0.995530 & -0.595562 & 0.985154 \\
$\mathbf{X 2}$ & 0.995530 & 1.000000 & -0.617250 & 0.992963 \\
$\mathbf{X 3}$ & -0.595562 & $-0,617250$ & 1.000000 & -0.623101 \\
$\mathbf{X 4}$ & 0.985154 & 0.992963 & -0.623101 & 1.000000
\end{tabular}

Many of the explicit relation numbers are greater than 0.8 , and some are as high as 0.9 , so it can be inferred that there is a serious multiple collinearity between variables.

By using the stepwise regression method, we further verify the existence of multiple collinearity, regress each explanatory variable to other explanatory $R^{2}$ variables, obtain their determinability coefficient and calculate their variance expansion factor VIF.

Table 3. Probability coefficient and variance expansion factor

\begin{tabular}{c|c|c|c|c}
\hline & $x_{1}$ & $x_{2}$ & $x_{3}$ & $x_{4}$ \\
\hline$R^{2}$ & 0.922 & 0.917 & 0.220 & 0.915 \\
\hline VIF & 12.82 & 12.04 & 1.28 & 11.76 \\
\hline
\end{tabular}

The model does have serious multiple collinearity. In order to overcome the influence of multiple collinearity, we use stepwise regression method to establish regression model.

\subsubsection{Regression Model}

\subsubsection{Least square regression}

The following table is obtained by least square regression of $\mathrm{Y}$ for each explanatory variable:

$$
\begin{array}{lcc}
\text { ls y c } x_{1}: & Y_{i}=1059.827+0.264037 x_{1} \\
\text { t value } & 2.789 & 10.897 \\
\text { p value } & 0.0191 & 0.00 \\
\mathrm{R}^{2}=0.922 & \overline{\mathrm{R}}^{2}=0.914 \\
& & \\
\text { Ls y c } \mathrm{x}_{2}: \mathrm{Y}_{\mathrm{i}}=576.296 & 0.096 \mathrm{x}_{2} \\
\text { t value } & 1.323 & 10.547 \\
\mathrm{p} \text { value } & 0.215 & 0.00 \\
\mathrm{R}^{2}=0.917 & \overline{\mathrm{R}}^{2}=0.909 & \\
& & \\
\text { Ls y c } \mathrm{x}_{3}: \mathrm{Y}_{\mathrm{i}}=44849-387.9011 \mathrm{x}_{3} \\
\text { t value } & 1.88 & -1.68 \\
\text { p value } & 0.088 & 0.123
\end{array}
$$




$$
\begin{array}{lcc}
\mathrm{R}^{2}=0.220 & \overline{\mathrm{R}}^{2}=0.14 \\
\text { L s y c }: \mathrm{x}_{4} \mathrm{Y}_{\mathrm{i}}= & 1574.86+ & 0.8614 \mathrm{x}_{4} \\
\mathrm{t} \text { value } & 4.468 & 10.399 \\
\text { p value } & 0.0012 & 0.00 \\
\mathrm{R}^{2}=0.915 & \overline{\mathrm{R}}^{2}=0.906 &
\end{array}
$$

The absolute values of the $\mathrm{R} 2$ and $\mathrm{t}$ values of the above data can be selected as the preliminary model according to the importance of the variables:

$$
Y_{i}=\gamma_{0}+\gamma_{1} X_{1}+\mu_{t}
$$

\subsubsection{Introduction of Basic Models}

Bring preliminary model and variables into the basic model one by one according to R-squared size.

Table 4. Parameter Estimates Table

Sample: $2007-2018$

Included observations: 12

\begin{tabular}{ccccc}
\hline \hline Variable & Coefficient & Std.Error & t-Statistic & Prob. \\
\hline \hline C & 1717.620 & 1208.245 & 1.421582 & 0.1929 \\
X1 & 0.275771 & 0.289782 & 0.951648 & 0.0431 \\
X2 & -0.068238 & 0.153929 & -0.443304 & 0.0488 \\
X4 & 0.577335 & 0.756892 & 0.762771 & 0.0463 \\
\hline \hline & & & & \\
R-squared & 0.927930 & Mean dependent var & 4921.123 \\
Adjusted R-squared & 0.900904 & S.D.dependent var & 1625.334 \\
S.E.of regression & 511.6472 & Akaike info criterion & 15.57435 \\
Sum squared resid & 2094263. & Schwarz criterion & 15.73598 \\
Log likelihood & -89.44610 & Hannan-Quinn criter. & 15.51451 \\
F-statistic & 34.33449 & Durbin-Watson stat & 1.285815 \\
Prob (F-statistical) & 0.000064 & &
\end{tabular}

During the process of gradual introduction, after $x_{1}$ is introduced, it can be found that the equation $R^{2}$ has improved; retained $x_{1}$ and $x_{3}$ continued to be introduced, $R^{2}$ not only without increasing but decreasing, so giving up $x_{3}$; continuing to introduce $x_{4}$, variable coefficient symbols and estimates can pass the t test, retention $x_{4}$. According to this order, the price function model of commercial housing in Shaanxi Province is as follows:

$Y=0.275771 X_{1}-0.068238 X_{2}+0.577335 X_{3}+1717.62$

\subsubsection{Heteroscedasticity test}

Assuming that the equation:

$H_{0}$ :Having the same variance

$H_{1}$ :Having heteroscedasticity

By using the White heteroscedasticity test method, the following table is obtained without checking the cross items:
Table 5. White heteroscedasticity test

Heteroskedasticity Test: White

\begin{tabular}{cccc}
\hline \hline F-statistic & 0.917210 & Prob.F(3,8) & 0.4749 \\
Obs*R-squared & 3.071122 & Prob.Chi-Square(3) & 0.3808 \\
Scaled explained SS & 0.930110 & Prob.Chi-Square(3) & 0.8182 \\
\hline
\end{tabular}

The results show that the $p$ value of the Obs*R-squared is $0.3808 / 0.3808>0.05$. The original hypothesis is accepted, which indicates that the equation does not have heteroscedasticity (homoscedasticity).

\subsubsection{Self-correlation test}

Assuming that the equation:

$H_{0}:$ No self-correlation

$H_{1}$ :There is autocorrelation

Using Lagrangian multiplier and partial autocorrelation coefficient test method, the default second order is obtained in Table 2

Table 6. LM Inspection

\begin{tabular}{cccc}
\multicolumn{4}{l}{ Breusch-Godfrey Serial Correlation LM Test: } \\
\hline \hline F-statistic & 0.672200 & Prob. F(2,6) & 0.5452 \\
Obs*R-squared & 2.196612 & Prob. Chi-Square(2) & 0.3334
\end{tabular}

Table 6 shows that the $\mathrm{P}$ value of the $\mathrm{F}$ test is $0.5452 / 0.5452>0.05$, so the original hypothesis is accepted and there is no autocorrelation.

\section{$\underline{\text { 3.2.2.5 Model Fit Regression }}$}

View-Actual,Fitted,Residual-Actual,Fitted, Residual Graph get Figure 2

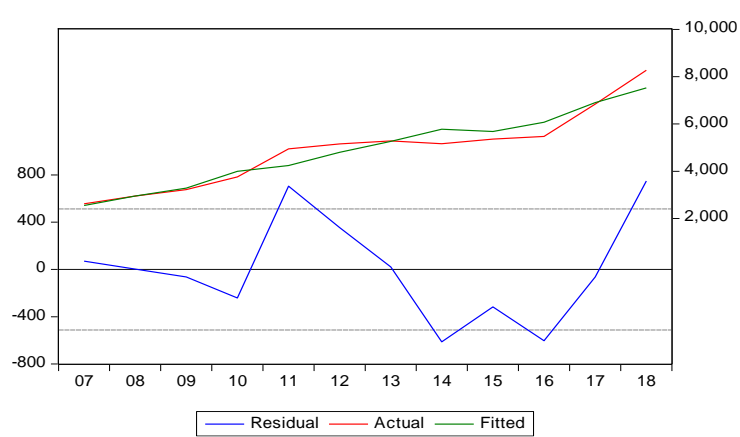

Figure 1 Fitting regression of model

\subsubsection{Model Conclusion Analysis}

After various tests and corrections, the final multivariate linear model is obtained:

$$
\mathrm{Y}=0.275771 X_{1}-0.068238 X_{2}+0.577335 X_{3}+1717.62
$$

Model description: the final multivariate model shows that for each increase of 100 million yuan in GDP, 
the price of commercial housing in Shaanxi Province will increase by 0.276 yuan per square meter, and the average wage of urban employed people will increase by 0.0682 yuan per square meter. For every 100 million yuan increase in the total output value of the construction industry in Shaanxi Province, the price of commercial housing in Shaanxi Province will increase by 0.09 yuan per square meter.[4]

\section{CONCLUSIONS}

In this paper, four influencing factors on the price of commercial housing in Shaanxi Province are selected, and three of them are selected as the final influencing factors. These three factors also explain the reasons for the rise of commercial housing prices in Shaanxi Province from three angles. Here for Shaanxi Province commercial housing price regulation and control put forward personal suggestions.

\subsection{Personal aspects}

When the government introduced "purchase restrictions" and other purchase policies, do not randomly listen to the letter "cannot buy after the purchase restrictions ", or because of the introduction of purchase restrictions and take advantage of the opportunity to buy a number of real estate, not only because of excessive demand and lead to soaring housing prices, but also for their own unwarranted economic burden[5].Some studies also show that, in fact, the psychological and behavioral factors of micro subjects do play a very important role in the real estate market, which will have an impact on the real estate market and housing prices. Therefore, in the face of the social phenomenon of soaring housing prices, it is necessary to guide residents to choose commercial housing suitable for their own economic situation when they choose to buy a house. Do not follow the trend to buy a house, according to the need to buy real estate.

\subsection{Government (national) level}

The Government should deliberately curb the phenomenon of speculative housing purchase, while limiting the price increase of real estate enterprises themselves, for some residents who have solved the housing problem and have better economic conditions, continue to buy commercial housing in order to increase value, maintain value or make profits, and use real estate as an investment method. As a result, the government should further raise housing prices, disturb the market, and is not conducive to the smooth and healthy development of the real estate market in our city. The government should adopt corresponding policies and give full play to the role of tax leverage. Synthesizes the entire market demand, the diversification household type, as far as possible the priority consideration, considers the function complete small household type, guarantees the market most basic rigid demand.[6]

\subsection{Business level}

As a supplier to meet the demand, in the face of the social masses because of excessive demand and bid up housing prices, should have their own way of regulation and control, cannot allow its growth. For perennial no one to buy idle real estate for low prices, clearance processing.

\section{REFERENCES}

[1] Liao, Z. Y. A Study on the Influencing Factors of Commercial Housing Price in China Based on Spatial Metering Model. Hunan University ,2015.

[2] Wang, Y. C. Measurement Study on the Influencing Factors of Commercial Housing Price Based on EViews in Jiangxi Province. Market Research, 2020, 4 :54-56.

[3] Sun, L. L. China's Urban Housing Price Fluctuation and Government Macro-control recently. Southwest University of Finance and Economics ,2006.

[4] Ji, N. Analysis and Forecast of Price Trend of Commercial Housing in Xi'an in the near future, Price and Market ,2009, 9:21-22.

[5] Kong, Y. A Review of Housing Price Volatility in Behavioral Economics Perspective. Journal of Chongqing University (Social Sciences Edition), 2017, 23 (1): 26-34.

[6] Wang, M. Considerations on the Development of Xi'an Real Estate Industry under Current Situation. Anhui Architecture, 2011,18 (5): 199-200. 